\title{
Thirteen is enough: the myosins of Dictyostelium discoideum and their light chains Martin Kollmar*
}

Address: Abteilung NMR basierte Strukturbiologie, Max-Planck-Institut für Biophysikalische Chemie, Am Fassberg 11, D-37077 Goettingen, Germany

Email: Martin Kollmar* - mako@nmr.mpibpc.mpg.de

* Corresponding author

Published: 20 July 2006

BMC Genomics 2006, 7:183 doi:10.1/86//47|-2164-7-183
Received: 14 March 2006

Accepted: 20 July 2006

This article is available from: http://www.biomedcentral.com//47I-2/64/7//83

(c) 2006 Kollmar; licensee BioMed Central Ltd.

This is an Open Access article distributed under the terms of the Creative Commons Attribution License (http://creativecommons.org/licenses/by/2.0), which permits unrestricted use, distribution, and reproduction in any medium, provided the original work is properly cited.

\begin{abstract}
Background: Dictyostelium discoideum is one of the most famous model organisms for studying motile processes like cell movement, organelle transport, cytokinesis, and endocytosis. Members of the myosin superfamily, that move on actin filaments and power many of these tasks, are tripartite proteins consisting of a conserved catalytic domain followed by the neck region consisting of a different number of so-called IQ motifs for binding of light chains. The tails contain functional motifs that are responsible for the accomplishment of the different tasks in the cell. Unicellular organisms like yeasts contain three to five myosins while vertebrates express over 40 different myosin genes. Recently, the question has been raised how many myosins a simple multicellular organism like Dictyostelium would need to accomplish all the different motility-related tasks.

Results: The analysis of the Dictyostelium genome revealed thirteen myosins of which three have not been described before. The phylogenetic analysis of the motor domains of the new myosins placed Myo IF to the class-I myosins and Myo5A to the class- $\mathrm{V}$ myosins. The third new myosin, an orphan myosin, has been named MyoG. It contains an $\mathrm{N}$-terminal extension of over 400 residues, and a tail consisting of four IQ motifs and two MyTH4/FERM (myosin tail homology 4/band 4.I, ezrin, radixin, and moesin) tandem domains that are separated by a long region containing an $\mathrm{SH} 3$

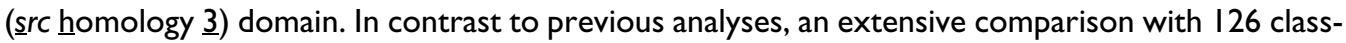
$\mathrm{VII}$, class-X, class-XV, and class-XXII myosins now showed that Myol does not group into any of these classes and should not be used as a model for class-VII myosins.

The search for calmodulin related proteins revealed two further potential myosin light chains. One is a close homolog of the two EF-hand motifs containing MlcB, and the other, CBPI4, phylogenetically groups to the ELC/RLC/calmodulin (essential light chain/regulatory light chain) branch of the tree.

Conclusion: Dictyostelium contains thirteen myosins together with 6-8 MLCs (myosin light chain) to assist in a variety of actin-based processes in the cell. Although they are homologous to myosins of higher eukaryotes, the myosins of Dictyostelium should be considered with care as models for specific functions of vertebrate myosins.
\end{abstract}




\section{Background}

Three kinds of molecular motor proteins have been identified so far: myosins, kinesins, and dyneins $[1,2]$. While kinesins and dyneins move on microtubule tracks, myosins are the only motors that use the energy of ATP hydrolysis to power movement along actin filaments. The first myosin was identified in skeletal muscle tissue, and subsequently a large number of proteins containing the myosin motor domain have been discovered in eukaryotic cells where they fulfill a variety of cellular functions from cell division, cellular locomotion, vesicle transport to muscle contraction [1].

Myosin proteins are typically divided into three major domains. The motor domain that is usually found at the $\mathrm{N}$-terminus contains the nucleotide and actin binding sites. The neck domain, following the motor domain, consists of a helical segment that binds specific myosin light chains or calmodulin. The target sequence for light chain binding is based on the consensus sequence IQxxxRGxxxR [3] and therefore termed the IQ motif. Myosins may have zero to over 15 IQ motifs in the neck region. The third domain is called the tail domain and contains class specific functional motifs that are responsible for the accomplishment of the different tasks of the myosins in the cell [1]. The classification of the myosins is based on the phylogenetic relation of the myosin motor domains. Altogether, up to 20 myosin classes have been assigned in recent reviews $[4,5]$. In addition, there are many myosins for which close homologs have not been found and which are therefore termed orphan myosins. Recently, two analyses of myosin proteins describing conflicting findings have been published [6,7]. Both disagree with previously established models of myosin evolution [reviewed in [5]], because of the erroneous data sets and analysis methods used. However, we have performed an exhaustive analysis of 1910 manually annotated myosins from 303 species that will be referred to in the analysis of the Dictyostelium discoideum myosins (F. Odronitz and M. Kollmar, submitted).

Different organisms contain only a subset of the classes but in many cases several homologs of the same class. For example, the Entamoeba histolytica genome reveals one class-I and one class-II myosin [8], while the Saccharomyces cerevisiae genome contains two class-I, one class-II, and two class- $\mathrm{V}$ myosins [9]. In contrast, more complex genomes show more diversity. The Caenorhabditis elegans genome contains 17 myosins belonging to seven classes, the Drosophila melanogaster genome contains 13 myosins belonging to ten classes, and the Homo sapiens genome reveals 40 myosins belonging to twelve classes. Plants do not have a large repertoire of classes but many homologs of the class-VIII and class-XI myosins (e.g. Arabidopsis thaliana contains 4 class-VIII and 13 class-XI myosin genes).
For the lower eukaryot Dictyostelium discoideum, 14 myosins or potential myosins have been reported so far. The first myosin identified, a class-II myosin, has been named mhcA (myosin heavy chain A) and all subsequently discovered myosins where named alphabetical (MyoA-M). For MyoF and MyoH only small fragments of the motor domain have been obtained while for MyoG and MyoL only potential loci have been identified. The class-I myosins (MyoA-E, MyoK) and the class-II myosin have unambiguously been assigned in the past [e.g. $[5,10]]$. MyoI has been classified as a class-VII myosin $[5,11]$, although the phylogenetic grouping has been very weak, while no similar myosin has been found to MyoM that has therefore been added to the orphan class. The closest homologues found for MyoJ came from the classXI myosins, a class only containing plant myosins, and it was therefore grouped to them $[12,13]$.

Almost all myosins exist at least as heterodimers by binding of light chains to the neck region. The light chains bind to the IQ motif and have an essential role in stabilizing the neck, so it can function as a rigid lever arm that swings relative to the motor domain to generate movement [14]. In addition, the light chains can be important regulatory sites, either through phosphorylation or by binding of $\mathrm{Ca}^{2+}$ [15]. The light chains belong to the family of calmodulin-related proteins. Most myosins are expected to bind calmodulins, while the class-II myosins always bind two specific calmodulin-related proteins, the essential and the regulatory myosin light chains. Recently, calmodulin-related proteins have been identified that specifically bind to a certain myosin, e.g. a light chain binding to Toxoplasma gondii Myo14A [TgMLC-1, [16]], or the light chain binding to Accanthamoeba castellanii Myo1C [AcMICLC, [17]]. For Dictyostelium discoideum, in addition to the essential and the regulatory myosin light chains two further specific light chains have been discovered. The class-I myosin MyoD binds a light chains that is phylogenetically related the AcMyo1C light chain [MlcD, [18]], and the class-I myosin MyoB forms a heterodimer with a light chain that is unique as it consists of only the half of a calmodulin-related protein [MlcB, [19]].

Dictyostelium is one of the most famous model organisms for studying motile processes in cells, especially those related to the actin cytoskeleton. Recently, the question has been raised how many myosins a simple multicellular organism like Dictyostelium would need to accomplish all the diverse motility-related tasks [10]. Here, the complete repertoire of myosin family proteins in the slime mold Dictyostelium discoideum is presented. The analysis revealed thirteen myosin proteins of which three have not been described so far. The new myosin family members are described and the already published myosins revised and partially reclassified. In addition, all members of the 
calmodulin-related protein family in Dictyostelium have been identified and analyzed to reveal the complete repertoire of myosin light chains.

\section{Results and discussion} Identification of Dictyostelium discoideum myosins The TBLASTN search with the motor domain of the Dictyostelium discoideum class-II myosin against the Dictyostelium genome sequence retrieved the previously identified and described genes and three new myosin genes (Table 1). Small fragments of two of these myosins (Myo1F and Myo5A, former $\mathrm{MyoH}$ ) have already been obtained in an investigation that combined low-stringency hybridization, physical mapping techniques, and PCR [20], but have not been verified in later studies. The study also revealed two additional loci that were referred to as myoG and myoL. The analysis of the Dictyostelium genome now showed that the myoG locus is a real locus, and the corresponding new myosin protein has been named MyoG. However, there is no evidence for further myosin genes and the myoL locus has most probably been assigned based on experimental artefacts.

The Dictyostelium cDNA database in Japan [21] was searched for the new myosin genes to confirm their expression (exclusion of pseudogenes) and gene structure, as the newly identified $m y o F, m y o H$, and $m y o G$ genes con- tain several introns (Table 1). However, the cDNA clones only cover the region around the last of the introns of Myo5A (MyoH). The extremely high AT content of Dictyostelium introns and the help of a multiple sequence alignment of over 1700 myosin motor domains (M. Kollmar, unpublished data) nevertheless allowed the unambiguous identification of the introns and, subsequently, the protein coding regions.

The Dictyostelium cDNA database also contains at least cDNA fragments for all previously reported myosins. The analysis of the genome sequence and the cDNA data revealed several major discrepancies to the published sequences (Table 2) in addition to many amino acid substitutions. The sequences derived from the genomesequencing project are without much doubt the correct sequences, because the genome sequence was build on high coverage and is completely in accordance with the cDNA data. Also, the sequences derived from the genome data are in agreement with the multiple sequence alignment while the published old sequences create strange insertions and substitutions. It is very unlikely that the differences are due to strain differences because the AX4 strain, that has been used to create the genome sequence and cDNA libraries, has been derived from the AX2 and AX3 strains used in earlier publications [22].

Table I: Members of the myosin gene superfamily in $D$. discoideum.

\begin{tabular}{|c|c|c|c|c|c|c|c|c|c|}
\hline $\begin{array}{l}\text { Protein } \\
\text { name }\end{array}$ & Gene name & $\begin{array}{c}\text { Size in } \\
\text { amino acids }\end{array}$ & Class & $\begin{array}{l}\text { No. of } \\
\text { introns }\end{array}$ & Chr. & $\begin{array}{l}\text { Gene accession } \\
\text { (GeneBank) }^{\mathrm{a}}\end{array}$ & $\begin{array}{c}\text { Protein } \\
\text { accession } \\
(\text { GenBank) }\end{array}$ & $\begin{array}{l}\text { dictyBaselD } \\
\text { (DDB...) }\end{array}$ & References \\
\hline MyolA & myoA & 994 & 1 & 2 & 3 & $\begin{array}{c}\frac{573909}{\text { AAFI01000066 }} \\
\end{array}$ & $\frac{\text { AAB207III }}{\underline{E A L 67246}}$ & 0215392 & {$[27]$} \\
\hline MyolB & myoB & 1111 & 1 & 2 & 5 & $\frac{M 26037}{\text { AAFI01000196 }}$ & $\frac{\text { AAA33229 }}{\text { EAL62866 }}$ & 0191351 & {$[48]$} \\
\hline MyolC & myoC & 1181 & 1 & 1 & 2 & $\frac{\mathrm{L35323}}{\text { AAFIOI000039 }}$ & $\frac{\text { AAC } 37427}{\text { EAL69121 }}$ & 0215355 & [49] \\
\hline MyolD & myoD & 1113 & 1 & 2 & 2 & $\frac{\text { L16509 }}{\text { AAFI01000030 }}$ & $\frac{\mathrm{P} 34109}{\mathrm{EAL69474}}$ & 0191347 & {$[50]$} \\
\hline Myole & myoE & 1003 & 1 & 3 & 5 & $\frac{106805}{\text { AAFIO1000I83 }}$ & $\frac{\text { AAA33201 }}{\text { EAL6307I }}$ & 0216200 & {$[51]$} \\
\hline MyolF & myoF & I07| & 1 & 1 & 5 & AAFIOI000I98 & EAL62822 & 0220021 & \\
\hline MyolG & myoK & 858 & 1 & 2 & 2 & $\begin{array}{c}\text { AF090534 } \\
\text { AAFI01000027 }\end{array}$ & $\begin{array}{l}\text { AAD47904 } \\
\text { EAL70180 }\end{array}$ & 0185086 & {$[52,53]$} \\
\hline MhcA & $m h c A$ & 2116 & 2 & 0 & 4 & $\frac{\text { MII938 }}{\text { AAFI01000135 }}$ & $\frac{\text { AAA33227 }}{\text { EAL64202 }}$ & 0191444 & [54] \\
\hline Myo5A & myoH & I77| & 5 & 3 & 5 & AAFIOI000209 & EAL62703 & $0|8844|$ & \\
\hline Мyо5В & myol & 2249 & 5 & 2 & 2 & $\begin{array}{c}\frac{U 42409}{\text { AAFIOI000020 }} \\
\underline{1}\end{array}$ & $\begin{array}{l}\text { AAA85186 } \\
\text { EAL7II208 }\end{array}$ & 0185050 & {$[12,13]$} \\
\hline MyoG & myoG & 3446 & n.c. & 3 & 2 & AAFIOI000034 & EAL69262 & 0167014 & \\
\hline Myol & myol & 2357 & n.c. & 3 & 2 & $\frac{\mathrm{L35321}}{\mathrm{AAFI01000027}}$ & $\begin{array}{l}\text { AAF06035 } \\
\text { EAL70I20 }\end{array}$ & 0185049 & {$[\mathrm{II}]$} \\
\hline МyoМ & mуом & 1737 & n.c. & 2 & 6 & $\frac{\mathrm{AF} 090533}{\mathrm{AAFI01000267}}$ & $\frac{\text { AAD47903 }}{\text { EAL6I255 }}$ & 0191100 & {$[53,55]$} \\
\hline
\end{tabular}

a The upper numbers refer to the published cDNA derived sequences, the lower numbers to the genomic sequences.

b The upper numbers refer to the protein sequences translated from cDNA, the lower to the sequences translated from genomic DNA. 
Table 2: Differences in the sequences of previously published genes and the genes obtained from the genome sequencing project.

\begin{tabular}{|c|c|c|}
\hline Protein name & $\begin{array}{l}\text { Sequence differences. The first residue/sequence is from the genome project, the } \\
\text { numbers indicate the position in the protein sequence. }\end{array}$ & $\begin{array}{l}\text { Example cDNA sequences covering } \\
\text { the revised residues. }\end{array}$ \\
\hline MyolA & 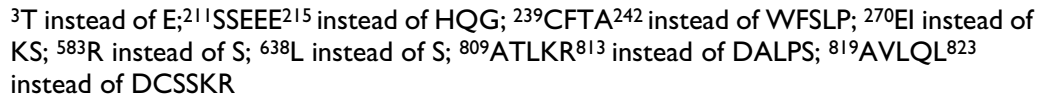 & AHM490, VFH8I0, AHHI86, VHP545 \\
\hline MyolB & ${ }^{207} \mathrm{~A}$ instead of $\mathrm{R} ;{ }^{365} \mathrm{R}$ instead of $\mathrm{K}$ & AFK24I, AHLI84, AHE272 \\
\hline MyolC & $\begin{array}{l}{ }^{479} \text { GADQKLLQSIAVCKSNPHFDTR } 500 \text { instead of VPIKSYFNPLPFVNQIHISILV } \\
813 \text { SSKSQVMVHP|823 instead of LQISSHGTPN }\end{array}$ & SLH38I, SHG368, AHF290 \\
\hline Myold & 613 no insertion of FGRI; ${ }^{694} \mathrm{~A}$ instead of $\mathrm{R} ;{ }^{837} \mathrm{~T}$ instead of $\mathrm{R}$ & AFJII6, VFN526 \\
\hline Myole & 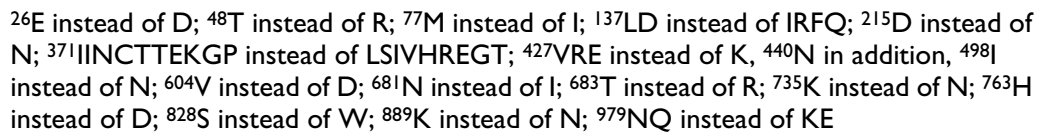 & VHK623, SHL808, AHG5I0, \\
\hline Мyo5В (МyoJ) & $\begin{array}{l}191 \mathrm{~F} \text { instead of } \mathrm{L} ;{ }^{284} \mathrm{~T} \text { instead of } \mathrm{A} ;{ }^{291} \mathrm{R} \text { instead of } \mathrm{G} ;{ }^{550} \mathrm{~K} \text { instead of } \mathrm{N} ;{ }^{865} \mathrm{QQ} \text { instead of } \\
\mathrm{HH} ;{ }^{1041} \mathrm{~K} \text { instead of } \mathrm{N} ;{ }^{1389} \mathrm{Q} \text { instead of } \mathrm{P}\end{array}$ & $\mathrm{AHL} 227$ \\
\hline
\end{tabular}

\section{Expression pattern of the new myosin genes}

The cDNA database is based on libraries of cells obtained from several different stages of the developmental cycle of Dictyostelium [23]. One library contains data from clones obtained at the so-called first finger stage $(14 \mathrm{~h}-16 \mathrm{~h})$ of development. A second library was constructed from vegetatively growing cells. A third library contains clones derived from "sexually competent cells" (cells are cultured in liquid medium in the dark, and are competent for fusion with opposite mating type cells), cells that are roughly equivalent to growth phase cells. The data supposed to contain full-length genes is based on libraries from cells at the following stages of the developmental cycle: axenically growing cells, cells developed on nitrocellulose filter to aggregation stage ( 8 hours), slug stage (16 hours) and early culmination stage (20 hours). For Myo5A (MyoH) and MyoG cDNA fragments have been obtained in all libraries containing the potentially fulllength genes indicating that these two myosins are expressed in all stages of the developmental cycle. However, only one gene fragment has been obtained for Myo1F from the library of full-length genes of axenically growing cells. The cDNA data is not supposed to reveal the complete expression pattern of all proteins at the different developmental stages. But the number of obtained clones and the occurrence in a specific library indicates that Myo1F might not be strongly expressed, and primarily expressed in vegetative cells. These conclusions have of course to be confirmed by further experimental data.

\section{Classification, nomenclature, and phylogenetic analysis} The classification and suggested revised nomenclature of the Dictyostelium myosins is summarized in Table 1 and shown in Figure 1. The general nomenclature for myosin proteins uses the term Myo followed by the class number (Arabic numeral) and the variant (Arabic letter). The class-
II myosins are exceptions as Mhc or Myh is used as abbreviation (leaving out the class number) followed by the variant designations as either Arabic letters or Arabic numerals. To not severely increase the number of classes, myosins that do not have a homolog in at least one other organism should be referred to as orphans. So far, the Dictyostelium myosins have not consistently been named according to that nomenclature. The phylogenetic analysis of over 1700 myosin motor domains (M. Kollmar, unpublished data) together with the completed sequence of the Dictyostelium genome now allows a revision. The new nomenclature does not severely change the old names as the class-II myosin stays untouched, the class-I myosins only get the class designation added with the exception of MyoK that will now be referred to as Myo1G, and MyoM is still an orphan myosin and will not be renamed as long as it cannot be grouped to a certain class. The newly identified MyoG (preliminarily named according to its locus) is also an orphan myosin and might be renamed as soon as further homologous myosins are derived. However, the classification of the other myosins, $\mathrm{MyoH}, \mathrm{MyoJ}$, and MyoI, is not that unambiguous.

A phylogenetic tree of 180 myosins of the classes V, VIII, and XI (including the former class-XIII myosins) does not group $\mathrm{MyoH}$ and MyoJ to any of the already assigned classes (Figure 2, additional file 1). Instead of assigning these myosins a new class, as it happened in the past e.g. for the classification of the Acetabularia cliftonii class-XIII myosins, I suggest to name MyoH and MyoJ Myo5A and Myo5B, respectively. Both myosins have a similar domain organisation as the class- $\mathrm{V}$ and the class-XI myosins. But because Dictyostelium separated from the Fungi/Metazoa lineage after the separation of the plants, $\mathrm{MyoH}$ and MyoJ should rather be referred to as class- $\mathrm{V}$ than class-XI myosins. This classification is supported by the analysis of 


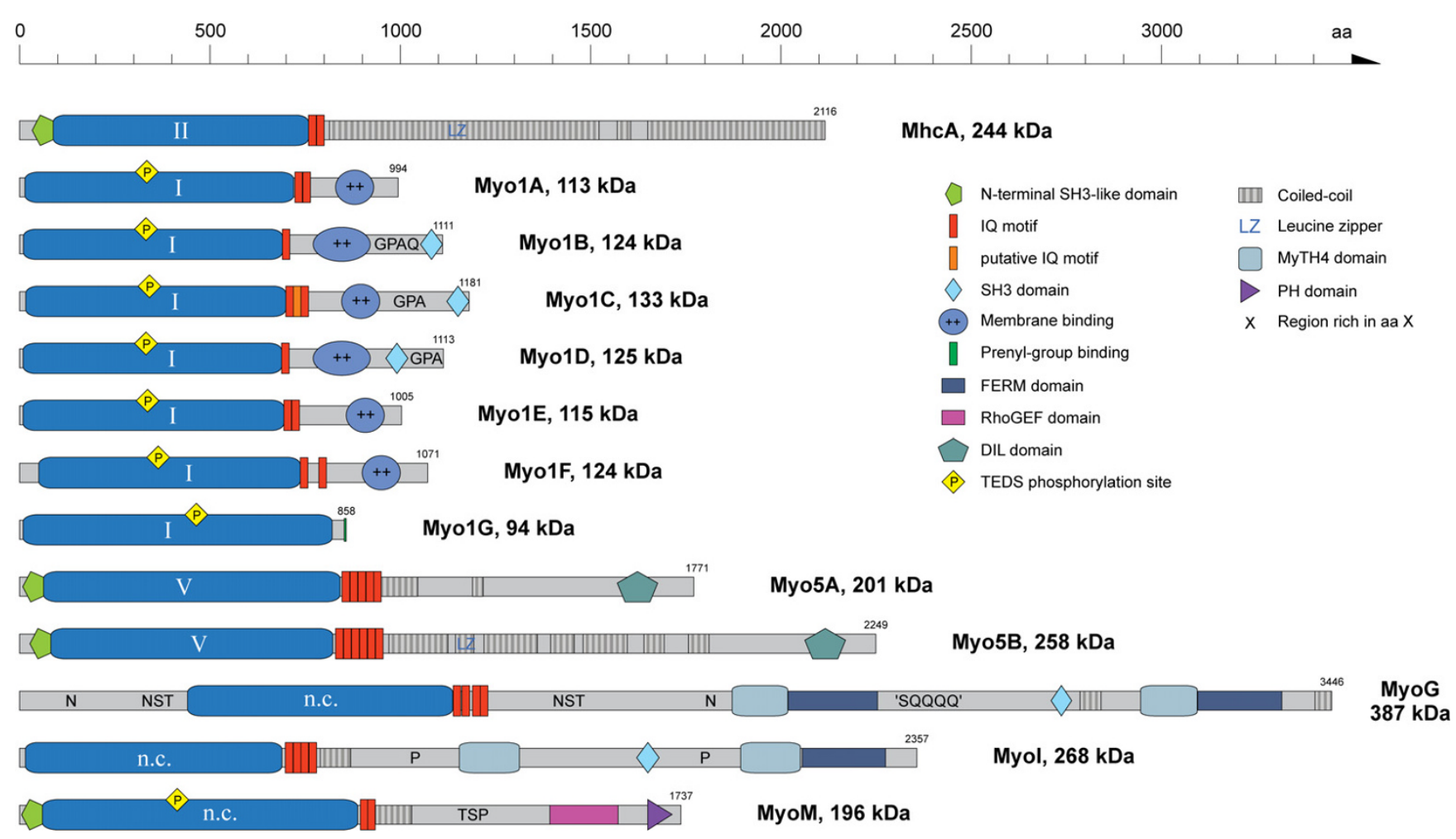

Figure I

Schematic diagram of the domain structure of the Dictyostelium discoideum myosins. The class designation is given in the motor domain of the respective myosin in Roman numerals. Orphan myosins have been designated n.c. (not classified). A colour key to the domain names and symbols is given on the right except for the myosin domain that is coloured in blue.

the over 1700 myosins that revealed $\mathrm{MyoH}$ and MyoJ to be closer related to the class- $\mathrm{V}$ myosins than to the plant myosins (M. Kollmar, unpublished data).

MyoI does not group to any of the designated classes containing myosins with MyTH4/FERM domains as is shown by the phylogenetic analysis of 126 myosin motor domains of classes VII, X, XV, and XXII (Figure 3, additional file 2). It does not group to the class-XXII myosins although it branches from the class-XXII myosins in the tree shown. The reason is that the branching occurs very close to the separation point of the other classes, and in phylogenetic trees including all classes MyoI also often branches very early from the class-X myosins. A close view at the protein sequence in the multiple sequence alignment shows that MyoI shares several class specific features off all four classes that prevent a better classification. In addition to the motor domain sequence, the domain organisation of MyoI is unique compared to members of the other classes (Figure 4). In contrast to class-VII myosins, MyoI does not have an N-terminal SH3-like domain, it has four instead of five IQ-motifs and it misses the first FERM domain. The tails of class- $\mathrm{X}$ myosins are different to that of MyoI as they are characterised by two consecutive PH (pleckstrin homology) domains followed by the MyTH/FERM tandem domain. The domain organisation of the class-XV myosin tails is similar to that of MyoI except that the mammalian myosins have a very long N-terminal domain, while the insect myosins miss the SH3 domain. Like MyoI, the class-XXII myosins do not have an N-terminal domain, but their tail domain is different containing two complete MyTH/FERM tandem domains but no SH3 domain. Thus, MyoI cannot be grouped to any of the already designated classes and should be considered as an orphan myosin. This implicates that MyoI cannot be considered as a specific model for class-VII myosins as it has been suggested earlier $[11,24]$. The Dictyosteliida diverged before the evolution of the Metazoa. MyoI therefore rather resembles a common ancestor of the four classes instead of grouping to one of them.

\section{Domain structure of the known myosins}

Most of the tail domains of the known myosins have already been described and functionally analysed in some detail $[25,26]$. While there is agreement on the determination of the larger tail domains like the class-I myosin membrane-binding and $\mathrm{SH} 3$ domains, or the Myo5B 


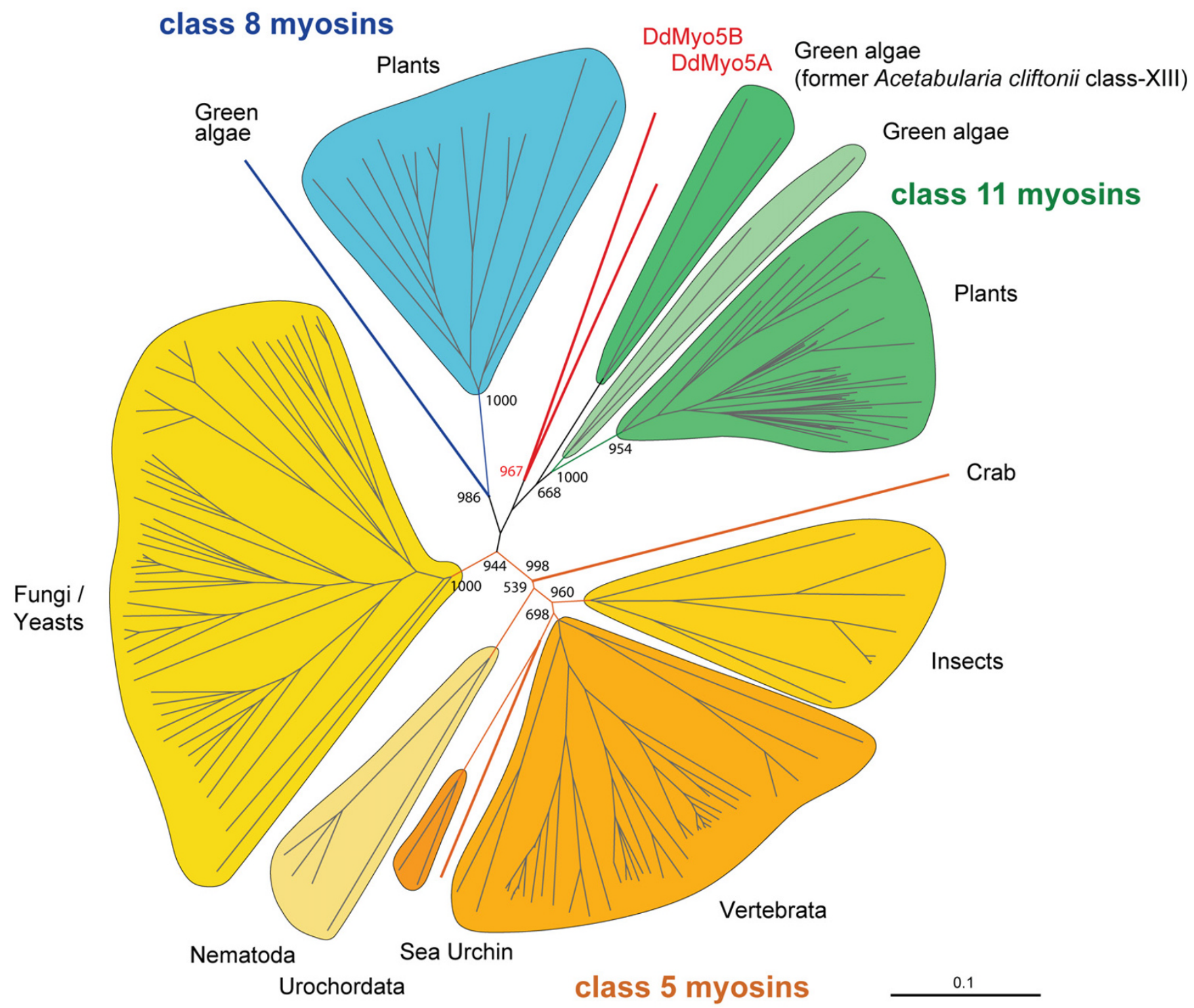

Figure 2

Phylogenetic tree of I 80 motor domains of class-V, -VIII, and -XI myosins (including the former class-XIII myosins). Amino acid sequences of the motor domains were aligned in a structure-guided manual alignment process. Support values for each internal branch were obtained by I,000 bootstrap steps. The values for the innermost branches are given. The scale bar corresponds to 0.1 estimated amino acid substitutions per site. See additional file I: SuppMat I for the complete tree containing all internal labels.

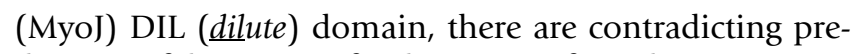
dictions of the IQ motifs. The IQ motif is a short sequence motif of alpha-helical structure that is able to bind calmodulin or calmodulin-like proteins. IQ motifs have been predicted in the past by using the general pattern IQxxxRGxxxR [3]. The multiple sequence alignment of the whole myosin family now allows a revision of the motif (M. Kollmar, unpublished data). According to the revised motif several IQ motifs are found in the Dictyostelium myosins that have not been recognised before (Figure 1 and Figure 5). The starting isoleucine in the motif is often substituted by other large hydrophobic amino acids. The glutamine at the second position is mainly conserved, except for some cases where it can be substituted by lysine, glycine, or glutamate. A very important position is the residue before the first arginine, that is almost always a large hydrophobic amino acid, in most cases an aromatic one. The first arginine is also highly conserved, except for a few cases where it is substituted by lysine, leucine, or isoleucine. The following glycine is not very conserved in IQ 
class 22 myosins

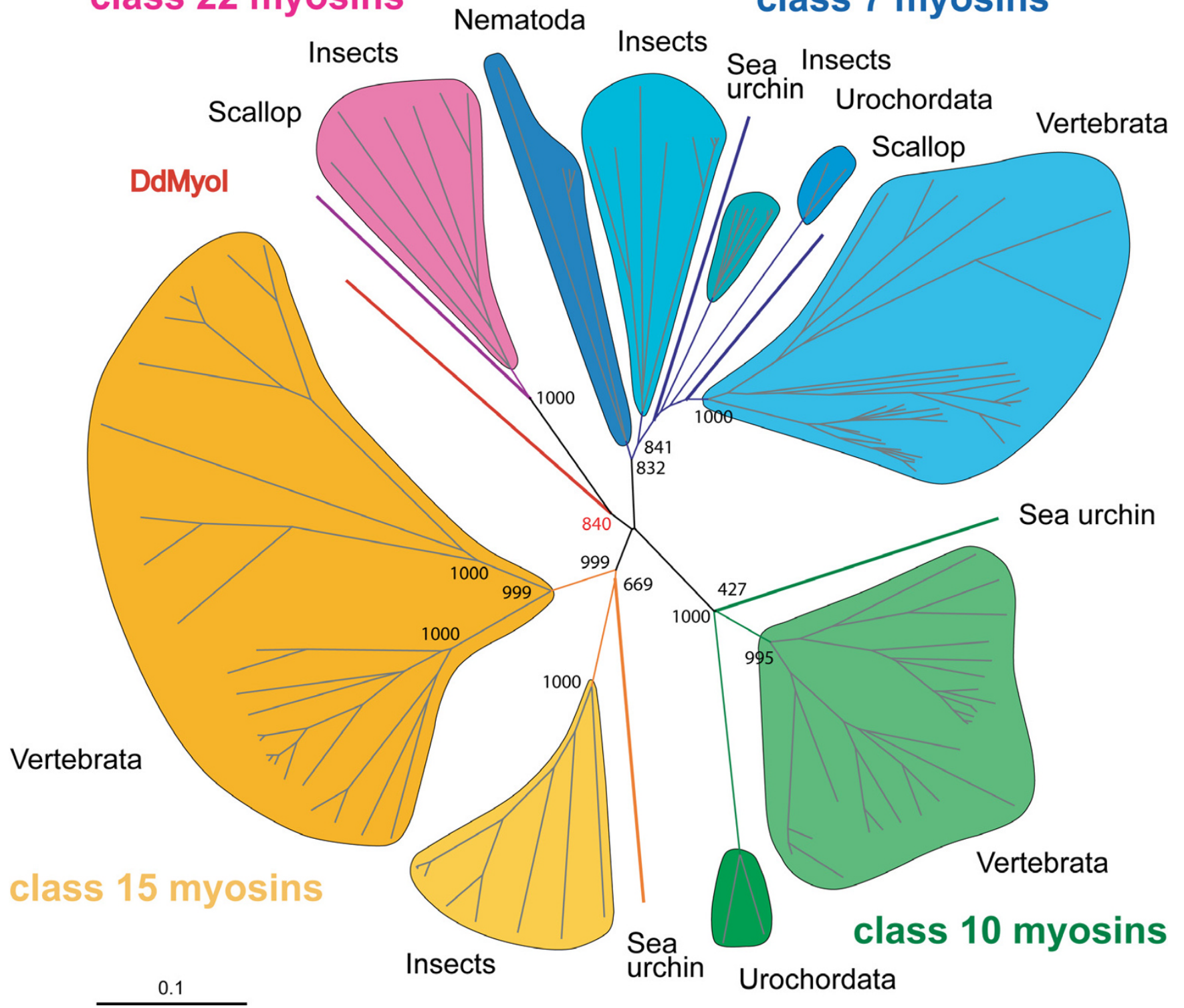

Figure 3

Phylogenetic tree of I 26 motor domains of class-VII, -X, -XV, and -XXII myosins. Amino acid sequences of the motor domains were aligned in a structure-guided manual alignment process. Support values for each internal branch were obtained by I,000 bootstrap steps. The values for the innermost branches are given. The scale bar corresponds to 0.1 estimated amino acid substitutions per site. See additional file 2: SuppMat2 for the complete tree containing all internal labels.

motifs of myosin tails. The position after that glycine is mainly occupied by large hydrophobic amino acids, in most cases aromatic residues, but histidines, asparagines, and glutamines are also found. The second arginine of the initial motif is also not very conserved. Using the revised motif, no IQ motif is predicted for Myo1G, one is predicted for Myo1B and Myo1D, and two are predicted for the other class-I myosins. Myo1C might contain a third IQ motif but then the packing of the light chains would be relatively dense. However, Myo1B binds a light chain that consists of only two EF-hand motifs [half the size of a normal calmodulin-related protein, [19]]. Two similarly small myosin light chains could easily bind to the two closely located IQ motifs of Myo1C. According to the new motif description MyoI is now predicted to contain four IQ motifs in contrast to earlier predictions of three IQ 


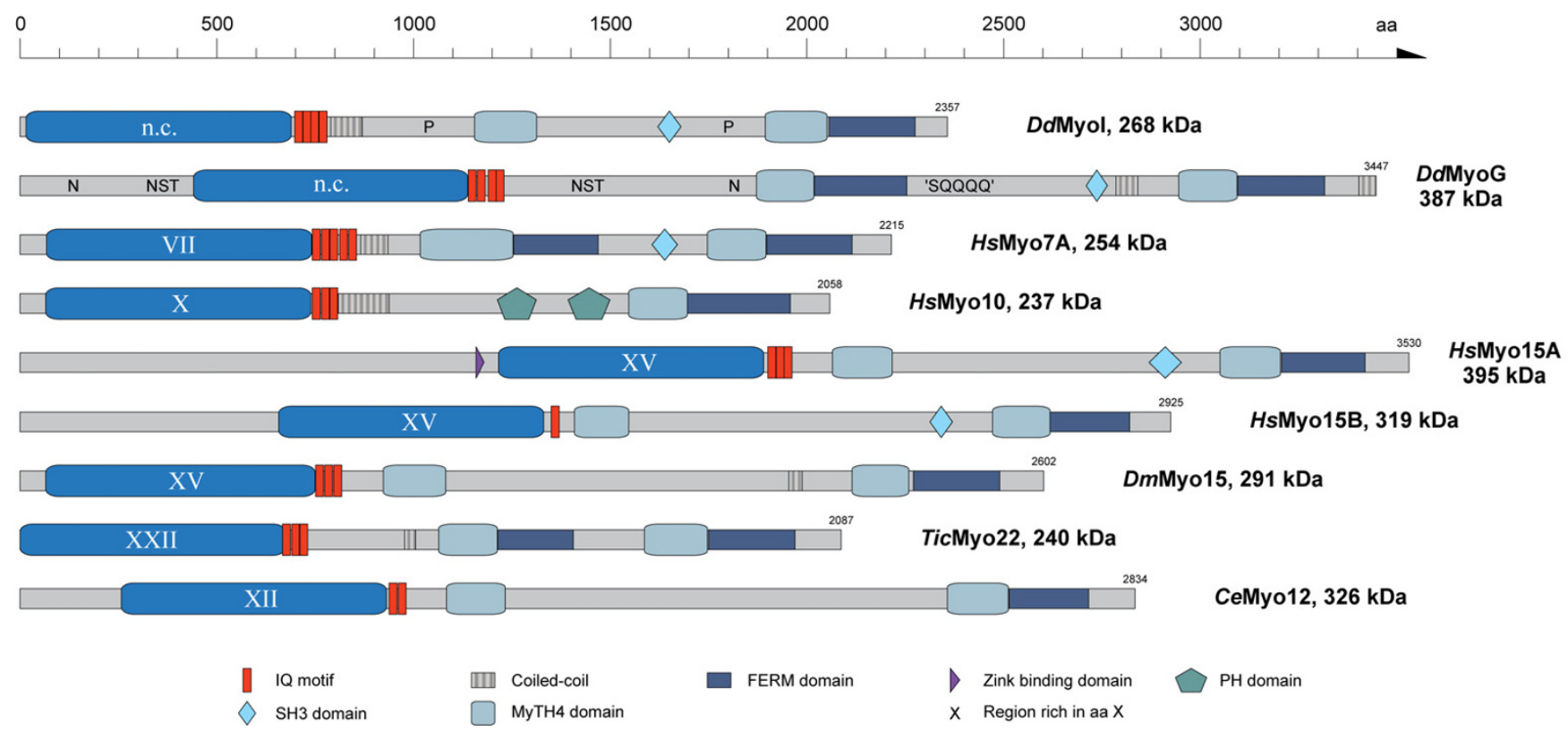

Figure 4

Domain organisation of examples of class-VII, -X,-XV, and -XXII myosins. The class designation is given in the motor domain of the respective myosin in Roman numerals. A colour key to the domain names and symbols is given on the bottom except for the myosin domain that is coloured in blue. For comparison, a myosin of class-XII is shown because its tail also contains MyTH4 and FERM domains, although class-XII myosins phylogenetically do not group at all to the other classes shown.

motifs [11], and Myo5B (MyoJ) contains six. The domain compositions of the newly identified myosins are described in more detail below.

\section{Domain structure of the newly identified and analysed myosins \\ Myo IF}

This myosin is the seventh class-I myosin found in the Dictyostelium genome. Based on the short fragment of the motor domain which has been obtained in an earlier PCR-based screen of the genome [27] it was already supposed to group to this subfamily. Its motor domain sequence is most similar to that of Myo1E. Unlike the other class-I myosins that contain only small N-terminal extensions to the motor domain of 8 to 15 residues it has an N-terminal domain of 50 amino acids. However, based on its sequence this small domain is unlikely to fold into a similar structure like the N-terminal domain of class-II myosins. Directly following the motor domain, Myo1F has two consecutive IQ motifs that are strong indicators for binding of calmodulin or a calmodulin-like myosin light chain. A short coiled-coil region has been predicted for the small region between the two IQ motifs. The short distance of only about 20 residues, however, makes it unlikely that Myo1F would be able to dimerize in that area. The remainder of the tail is similar to those of Myo1A or Myo1E predicted to be all $\alpha$-helical. In the cen- tre of the tail there is a domain rich in basic residues and it is therefore outlined as membrane binding domain in analogy to those of the other class-I myosins. Whether this region really binds to membranes has to be shown.

\section{Myo5A (former $\mathrm{MyoH}$ )}

Myo5A seems to be the smaller brother of Myo5B (MyoJ). Both are phylogenetically closely related and show similar domain organisations. Altogether, Myo5A (MyoH) is 480 aa shorter in length. It also has an N-terminal SH3-like domain, but the N-terminal extension is not as long as for Myo5B (MyoJ). In contrast to Myo5B (MyoJ), it has three additional long insertions into surface loops of the motor domain that are not observed in any other Dictyostelium myosin sequence. It has five instead of six IQ motives for binding of light chains, and the coiled-coil region is predicted to be considerably shorter than that of Myo5B (MyoJ). Except for the DIL domain at the C-terminus of the tail there is no further sequence similarity between the two Myo5 tail sequences.

\section{MyoG}

MyoG does not group to any of the class-VII, class-X, class$\mathrm{XV}$, or class-XXII myosins, or any other myosin, and is therefore designated an orphan myosin. MyoG is one of the longest myosins of the whole family. It has an N-terminal domain of 440 residues that does not show any 


\begin{tabular}{|c|c|c|}
\hline & & . . . . . . . . . . | | \\
\hline MhcA IQ1 & 763 & E I I KA - I QAATRGW I ARKVYK \\
\hline IQ2 & 789 & TVAARI - IQQNLRAYIDFKSWF \\
\hline Myo1A IQ1 & 724 & NDLATK - I GSVWKMYKQRKWY L \\
\hline IQ2 & 746 & $T L A A|K-| Q R T Y R G W L L V R E C V$ \\
\hline Myo1B IQ1 & 695 & FDCTAK - I QKAFRNWKAKKHS L \\
\hline Myo1C IQ1 & 702 & HDMASR-IKNAYRNYKAFQFEO \\
\hline IQ2 & 723 & $--S N R-I K N A F R N Y K L Y R Q R Q$ \\
\hline IQ3 & 741 & $\cdots A Q T-I Q G Y F R A W K Q A S P F F$ \\
\hline Myo1D IQ1 & 691 & F TYANK - LQRFF LRF TLMSYYY \\
\hline Myo1E IQ1 & 697 & PR IVTL - IQKTWRGYRARSKWN \\
\hline IQ2 & 719 & RKAAIK-IQLFYRSYRYKKWFR \\
\hline Myo1F IQ1 & 740 & PS IVI T - I QRVWRGYKVRKWYK \\
\hline IQ2 & 780 & KNSANL - IQTYYLRYKVLTYIK \\
\hline Myo5A IQ1 & 844 & I NSATF - I QK I WRGYTDRKAYT \\
\hline IQ2 & 867 & KHSS I Y - FQSLIRSYLQQLEYN \\
\hline IQ3 & 892 & ENSA I H - LQSL I RTNELEKQF \\
\hline IQ4 & 915 & LSTTIH - FQSLLRRLEDSKEFN \\
\hline IQ5 & 941 & IKK I VK - I QS LWRSNLAKKQLK \\
\hline Myo5B IQ1 & 825 & DRSATV - I QKRWKGYLYRKRYK \\
\hline IQ2 & 848 & RDASLI-IQTKLRSVHAKQQLS \\
\hline IQ3 & 873 & THSA I L - I QKVWRAHRDRVQYQ \\
\hline IQ4 & 896 & RDASLQ - LQTVMRRHLFSEQVI \\
\hline IQ5 & 921 & ENAA I I - LQTK IRQ I LSKREVD \\
\hline IQ6 & 944 & LRG I I L - IQARWRMKLAKRVY | \\
\hline MyoG IQ1 & 1141 & VRCAFT - I QS TWRMYLTRKRF I \\
\hline IQ2 & 1164 & KSA IVI - IQKNTRRWLVQKRYQ \\
\hline IQ3 & 1187 & KQAALI-LESFSRMVIFRAPYL \\
\hline IQ4 & 1210 & $R Q A A \mid A-I Q T H L R S L L S K D Y S Y$ \\
\hline Myol IQ1 & 692 & LKKVTL - I QSVWRMYRCKKRYC \\
\hline IQ2 & 715 & RASAKI-LGAAMLSHSSRRDFG \\
\hline IQ3 & 738 & $R Q A \vee Q R-I K G F F K M L T Y Q K Q F K$ \\
\hline IQ4 & 761 & Q INLR I - VQNN|RSF|ARRHSR \\
\hline MyoM IQ1 & 889 & VDS VLK-IQAFFKM IKIRNQYK \\
\hline IQ2 & 912 & KESSLF-LQTL|RAQRAKKDFE \\
\hline
\end{tabular}

Figure 5

Alignment of the putative IQ motifs of the Dictyostelium myosins. The alignment shows the $\mathrm{IQ}$ motifs of the myosins. The numbers at the beginning indicate the position in the full-length sequence. The gap has only been introduced to facilitate the identification of the IQ residues.

homology do other proteins. The sequence in the N-terminal domain contains long stretches of consecutive asparagines and serines that are typical for many Dictyostelium proteins [28]. The head domain is followed by four IQ motifs. The C-terminal tail is characterised by two MyTH4/FERM tandem domains that are separated by a long region containing an SH3 domain and a short predicted coiled-coil region. The regions between these recognised domains also contain many stretches of consecutive polar residues. An outstanding case is the nine-fold consecutive repeat of the motif 'SQQQQ'. The C-terminal end of the tail contains a second predicted coiled-coil region. The coiled-coil domains in myosins are normally located directly behind the IQ motifs and are responsible for dimerisation. MyoG might also exist as a dimer in vivo, but the heads are not expected to move on actin filaments in a similar hand-over-hand mechanism as has been found for other myosin dimers like class-V myosins [29].

\section{Structural features of the myosin motor domains}

The myosins of Dictyostelium contain several protein specific extensions to surface loops of the motor domain of class-II myosin (Fig. 6). The most prominent loop-extension is the insertion of $\sim 130$ amino acids into loop- 1 of Myo1G. Except for members of an arthropoda specific myosin class, that contain loop- 1 extensions of up to 300 amino acids [30], this is by far the longest loop-1 of all myosins. Myo5B (MyoJ) also contains a considerably longer loop-1 (20 residues in addition to loop-1 of MhcA). Loop-1 has been implicated in influencing access to the nucleotide-binding site. It has been shown in an analysis of chimeric loop-1 mutants of smooth muscle myosin that the mobility of this loop correlates to the rate of ADP release [31]. Larger and more flexible loops resulted in faster rates of ADP release. For class- $\mathrm{V}$ myosins, the rate-limiting step in the catalytic cycle is ADP release [32], a necessity for these myosins to walk over long distances along the actin filaments without detaching. Based on these results, Myo5B (MyoJ) might be a very unconventional class- $\mathrm{V}$ myosin with a fast rate of ADP release. It will be very interesting to see whether Myo5B (MyoJ) is still a long-distance cargo transporting myosin as the other homologs of the class.

Loop-2 has been shown to be involved in both weak and strong binding interactions with actin [33]. According to this study, especially positively charged residues strengthen the binding to actin. MyoG and MyoM contain long extensions of loop-2 compared to MhcA, but the sequences contain mainly glycines, prolines, and polar amino acids. Thus, both myosins are not expected to have considerably different actin-binding properties. Loop- 4 is the loop that is furthest removed from the actin surface as has been suggested from actomyosin models derived from electron microscopy. Except for some class-I, the insect class-V, some class-XVII, and some apicomplexa myosins, almost all myosins have a loop- 4 of similar length. The loop has been suggested to be involved in either interactions with actin or regulatory proteins that are bound to actin [34]. For the class-I myosin myr1 from rat, it has been shown that a head fragment localizes to the same highly dynamic actin structures at the cell cortex as the full-length construct and not to the actin filaments that are regulated by tropomyosin [35]. An extended loop-4 might be responsible for this localisation as it might hinder binding to the tropomyosin stabilized less dynamic actin filaments as they occur in stress fibers. Myo5A (MyoH) contains one of the longest loop-4 of all myosins and might therefore only bind to the dynamic actin structures at the cell cortex and not to actin structures that are stabilized by other proteins. 


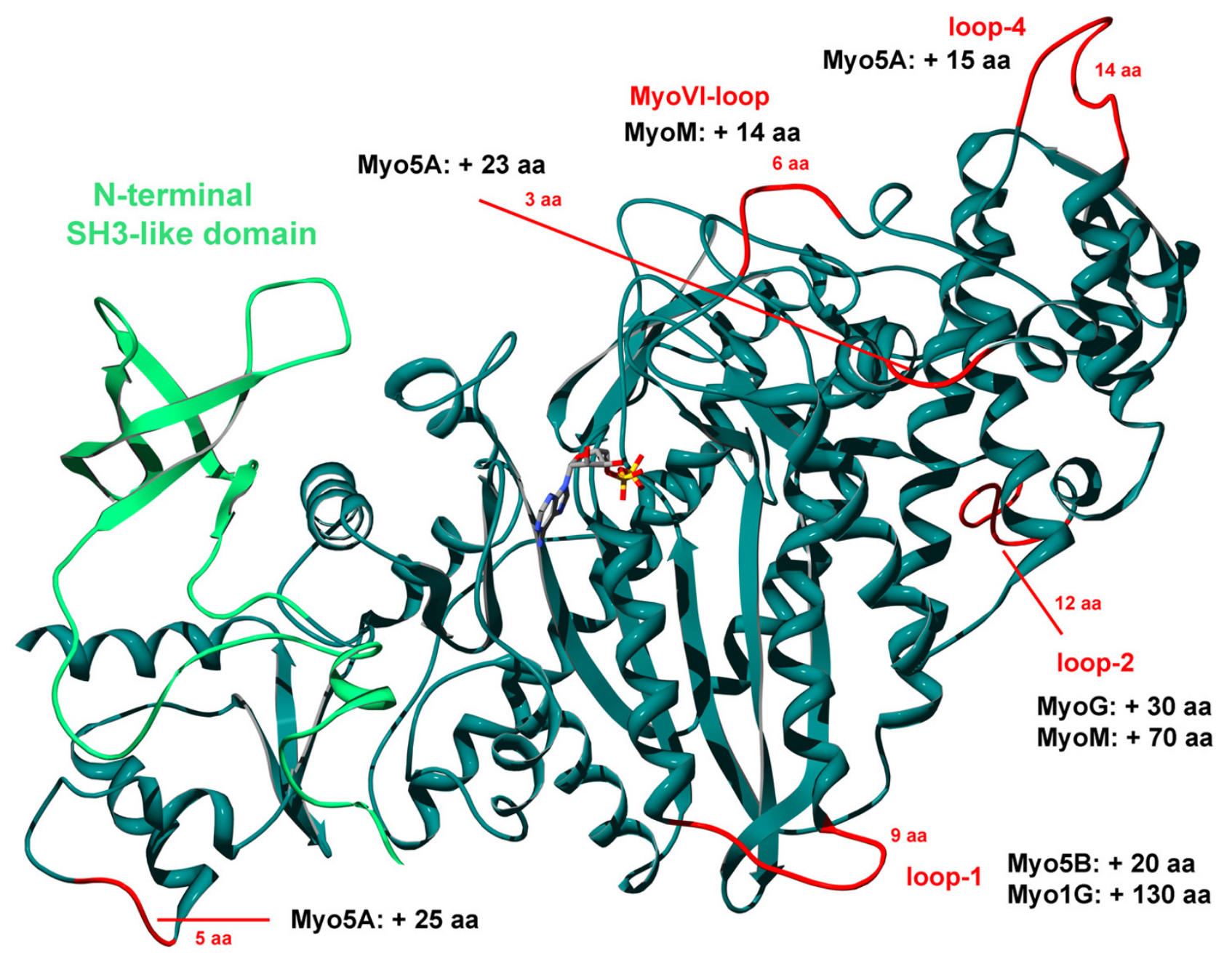

Figure 6

Structure of the motor domain of Dictyostelium MhcA. Structure of the motor domain of Dictyostelium MhcA (PDB: Ig8x) highlighting loops for which some of the Dictyostelium myosins have long insertions. The red numbers indicate the length of the loops for MhcA. The approximate lengths of the insertions are given for the respective myosins.

Myom has an extended loop at the same position where the class-VI myosins have one of their prominent insertions. This loop has been suggested to affect nucleotide binding by changing the conformation of a following loop [36]. This loop therefore protrudes within the nucleotide-binding pocket, resulting in a decrease in nucleotide accessibility. The functions of the other two surface loops, for which Myo5A (MyoH) has long extensions, have not been analysed so far.

\section{Phylogenetic analysis of calmodulin-like proteins in Dictyostelium}

An iterative TBLASTN search of the Dictyostelium genome data, starting with the sequence of Dictyostelium calmodulin A (DdCalA), revealed 35 CBPs (calcium-binding pro- tein) that exclusively contain EF-hands motifs (Table 3). While 32 CBPs contain four EF-hands, three contain only two EF-hand motifs (MlcB, MLC-1, and CBP10). 22 CBPs have already been described in the literature. To classify the remaining 13 CBPs and to identify those that could potentially function as myosin light chains, the Dictyostelium EF-hand proteins were compared with EF-hand containing proteins from Saccharomyces cerevisiae, Schizosaccharomyces pombe, Caenorhabditis elegans, Drosophila melanogaster, Homo sapiens, and some specific myosin light chains from other organisms. The obtained 176 calmodulin-related proteins were manually aligned and a phylogenetic tree created (Figure 7, additional file 3). 
Table 3: Members of the myosin light chain, calmodulin and calmodulin-related gene superfamily in $D$. discoideum.

\begin{tabular}{|c|c|c|c|c|c|c|c|c|}
\hline Protein name & Gene name & Size in aa & No. of introns & Chr. & $\begin{array}{l}\text { Gene accession } \\
\text { (GenBank) }\end{array}$ & $\begin{array}{c}\text { Protein } \\
\text { accession } \\
\text { (GeneBank) }\end{array}$ & $\begin{array}{l}\text { dictyBaselD } \\
\text { (DDB...) }\end{array}$ & References, comments \\
\hline ELC & $m l c E$ & 150 & I & 3 & AAFIOI000052 & EAL68102 & $02148 \mid 3$ & {$[56,57]$} \\
\hline RLC & $m / c R$ & 161 & 2 & 2 & AAFIOI000032 & EAL69338 & $0|85| 46$ & [58] \\
\hline MlcB & BC5V2_0_014I7 & 73 & 2 & 5 & AAFIOI000224 & EAL62399 & 0188713 & [19] \\
\hline MlcD & $m / c D$ & 147 & 2 & 3 & AAFIOI000052 & EAL68131 & 0214812 & [18] \\
\hline $\mathrm{MLCl}$ & BC5V2_0_0II63 & 80 & 2 & 5 & AAFIO1000214 & EAL62662 & 0219456 & \\
\hline CalA & calA & 152 & 3 & 3 & AAFI0I000060 & EAL67642 & 0214955 & [59] \\
\hline CalB & calB & 149 & 2 & 1 & AAFI010000II & EAL7I901 & 0191193 & [60] \\
\hline Calcineurin I & BC4V2_0_01538 & 183 & 3 & 4 & AAFI01000129 & $\overline{\text { EAL6444I }}$ & 0218775 & \\
\hline Calcineurin2 & $c n b A$ & 180 & 3 & 1 & AAFI01000009 & $\overline{\text { EAL73175 }}$ & 0191204 & \\
\hline CBPI & $c b p A$ & 156 & 1 & 2 & AAFIOI000042 & EAL6888I & 0185026 & {$[61]$} \\
\hline CBP2 & $C B P 2$ & 168 & 2 & 1 & AAFI01000009 & EAL73181 & 0191196 & {$[62]$} \\
\hline CBP3 & $c b p C$ & 166 & 3 & 4 & AAFI01000093 & EAL65573 & 0191405 & $\begin{array}{c}\text { [63], cluster with } c b p C \text {, } \\
c b p G, c b p F, C B P I 4\end{array}$ \\
\hline CBP4a & $c b p D I$ & 162 & 3 & 4 & AAFIOI000087 & EAL658I5 & 0219925 & [64] \\
\hline CBP4b & cbpD2 & 162 & 3 & 4 & AAFI01000086 & EAL65870 & 0191416 & [64] \\
\hline $\mathrm{CBP} 4 \mathrm{c}$ & BC4V2_0_01277 & 145 & 2 & 4 & AAFI01000124 & $\overline{\text { EAL64575 }}$ & 0186519 & pseudogene? \\
\hline CBP5 & $c b p E$ & 180 & 2 & 2 & AAFI01000027 & EAL69942 & 0185183 & {$[37]$} \\
\hline CBP6 & $c b p F$ & 174 & 3 & 4 & AAFI01000093 & EAL65572 & 0191383 & [37] \\
\hline CBP7 & $\operatorname{cbpG}$ & 169 & 3 & 4 & $\overline{\mathrm{AAFIO} 1000093}$ & $\overline{\text { EAL6557I }}$ & 0191382 & [37] \\
\hline CBP8 & $c b p H$ & 165 & 2 & 5 & AAFI0100018I & EAL63115 & 0191153 & [37] \\
\hline CBP9 & $c b p l$ & 163 & 3 & 2 & AAFIOI000022 & $\overline{E A L 7 I 05 I}$ & 0185027 & [37] \\
\hline CBPIO & JC2V2_0_03060 & 107 & 0 & 2 & AAFIOI000044 & EAL68782 & 0169106 & \\
\hline CBPII & BC4V2_0_02040 & 192 & 1 & 4 & AAFIOI000I45 & EAL63932 & 0187233 & No EST \\
\hline CBPI2 & BC4V2_0_00355 & 171 & 3 & 4 & AAFI0I000093 & EAL65589 & 0185595 & \\
\hline CBPI3 & BC4V2_0_00374 & 102 & I & 4 & AAFI01000093 & EAL65599 & 0185615 & pseudogene? \\
\hline CBPI4 & BC4V2_0_0II 73 & 139 & 1 & 4 & AAFI01000121 & $\overline{\text { EAL64796 }}$ & 0186418 & \\
\hline Frequenin I & cbpJ & 194 & I & I & AAFI010000II & $\overline{\text { EAL72455 }}$ & 0231009 & {$[65]$} \\
\hline Frequenin2 & $c b p K$ & 192 & 1 & 2 & $\frac{\text { AAFIOI000027 }}{\text { AY } 655132}$ & $\frac{\text { EAL70072 }}{\text { AAT72748 }}$ & 0167922 & {$[65]$} \\
\hline Frequenin 3 & $c b p L$ & 191 & 2 & 5 & AAFI01000187 & EAL630I4 & 0231012 & {$[65]$} \\
\hline Frequenin 4 & $c b p M$ & 183 & 2 & 4 & AAFIOI000I35 & EAL64210 & 0231014 & [65] \\
\hline Frequenin 5 & $n c s A$ & 186 & 2 & 2 & AAFIOI000030 & EAL69716 & 0231007 & [65] \\
\hline Frequenin 6 & JC2V2_0_01524 & 185 & 1 & 2 & AAFIO1000027 & EAL7007I & 0167921 & cluster with $c b p K$ \\
\hline Frequenin7 & JC2V2_0_01529 & 225 & 3 & 2 & AAFI01000027 & $\overline{\text { EAL70283 }}$ & 0217470 & \\
\hline Calfumirin & cafA & 169 & 3 & 3 & AAFIOI000052 & EAL68086 & 0214954 & {$[66]$} \\
\hline CentrinA & $\operatorname{cen} A$ & $15 \mid$ & 3 & 5 & AAFI01000171 & EAL63239 & 0219932 & \\
\hline CentrinB & $\operatorname{cen} B$ & 150 & I & 5 & AAFI01000056 & EAL67875 & 0220501 & \\
\hline
\end{tabular}

According to the phylogenetic tree, 16 of the Dictyostelium CBPs (CBP1-13, calfumirin) do not belong to an already named class but are closely related to the frequenins. CBP4c is very similar to CBP4a and CBP4b, but the N-terminus could not be identified. CBP13 is a protein fragment, missing the $\mathrm{N}$-terminus as well as the C-terminus, and is very similar to CBP12. СBP4c and СBP13 are therefore most probably pseudogenes. Those members of this group, that have already been identified, belong to developmentally regulated genes. Their distinct spatial expression patterns suggested that they might be involved in morphogenesis [37]. Seven of the Dictyostelium CBPs belong to the frequenin class. The members of the frequenin class are also highly developmentally regulated. An interaction with a myosin family protein has not been described in the literature for any member of this group of any organism. Dictyostelium also contains two centrins and two proteins grouping to the calcineurin family.

So far, only the ELC and RLC myosin light chains as well as calmodulin subfamily proteins have been shown to bind to the IQ motifs of myosins. The exceptions are the myosin light chain of Toxoplasma gondii Myo14A [TgMLC1, [16]], the light chain of Accanthamoeba castellanii Myo1C [AcMIMLC, [17]], and, identified in Dictyostelium, a light chain of Myo1D that is phylogenetically related the AcMyo1C light chain [MlcD, [18]], and a light chain that binds to Myo1B [MlcB, [19]]. Next to MlcD and MlcB, Dictyostelium contains one ELC and one RLC myosin light chain that bind to MhcA. For Saccharomyces cerevisiae it has been shown that the ELC (also termed Mlc1p) not only 


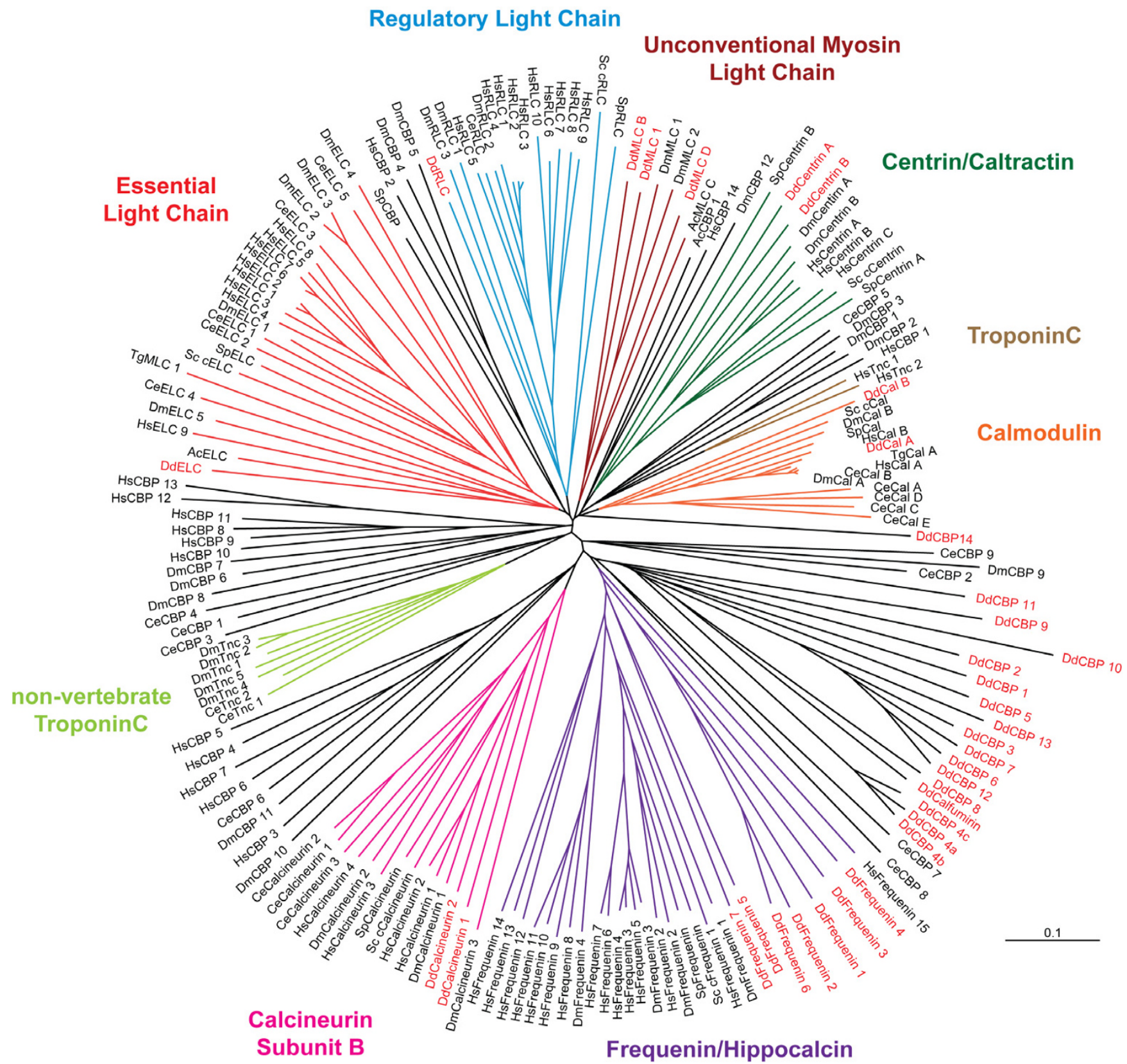

Figure 7

Phylogenetic tree of calmodulin-related proteins. Amino acid sequences of the calmodulin-related proteins were aligned manually. Support values for each internal branch were obtained by I,000 bootstrap steps. The scale bar corresponds to 0.1 estimated amino acid substitutions per site. See additional file 3: SuppMat3 for the complete tree containing all internal labels.

binds to the class-II myosin, but also to the class-V myosin Myo2p. Chicken myosin-5A even binds two different ELCs next to calmodulin. Therefore, the Dictyostelium ELC is also expected to participate in binding to the class- $\mathrm{V}$ myosins. Dictyostelium also contains two members of the calmodulin subfamily that have not specifically been shown to bind to myosins, but are highly expected to in accordance with results obtained for other organisms. The analysis also revealed another CBP containing two EFhand motifs that is most closely related to MlcB. It is therefore also highly expected to bind to a myosin, and termed MLC-1. As Myo1B and Myo1D bind a specific light 
chain each, and Myo1C is the closest homolog of the remaining class-I myosins, MLC-1 might be the specific light chain for Myo1C, but this has of course to be proven by biochemical experiments.

CBP14 does not group to any specific class but is more similar to the members of the calmodulin/ELC/RLC part of the phylogenetic tree then to the developmentally related CBPs. If it were able to function as a myosin light chain, then it would be the founding member for another specific myosin light chain class.

\section{Conclusion}

The analysis of the Dictyostelium discoideum genome revealed thirteen members of the myosin family of which three have not been described before. The phylogenetic analysis of their motor domains placed seven myosins to the class-I myosins (Myo1A to Myo1G, Myo1F is a new member), one to the class-II myosins (MhcA), and two, of which Myo5A (MyoH) has newly been identified, to the class- $\mathrm{V}$ myosins. Three myosins (MyoG, Myol, and MyoM) do not have a close homolog in any other organism and could therefore not be classified. In contrast to previous analyses, an extensive comparison with 126 class-VII, class-X, class-XV, and class-XXII myosins now showed that MyoI does not group into any of these classes and can not be used as a model for class-VII myosins. The third new myosin has been named MyoG. It contains an $\mathrm{N}$-terminal extension of over 400 residues, and a tail consisting of four IQ motifs and two MyTH4/FERM tandem domains that are separated by a long region containing an SH3 domain. Although its tail organisation is similar to that of class-VII myosins, the motor domain of MyoG does not group into any existing class.

Four specific myosin light chains have been identified so far (ELC, RLC, MlcB, MlcD) next to two calmodulins. The analysis of the genome revealed another protein containing two EF-hand motifs that is closely related to MlcB. Based on its phylogenetic relationship it is highly expected to be a myosin light chain. A further calmodulinrelated protein, termed CBP14, phylogenetically groups to the ELC/RLC/calmodulin branch of the tree and might therefore also be a myosin light chain, although it does not have a close homolog in other model organisms.

\section{Methods \\ Identification of Dictyostelium myosins and calmodulin related proteins}

The full-length sequences of ten of the thirteen Dictyostelium myosins have been reported in the literature (Table 1). Partial sequences of Myo1F (MyoF) and Myo5A ( $\mathrm{MyoH})$ have already been reported [27] and were used as basis for the manual assembly of the genes from clones published by the Dictyostelium Genome Sequencing
Project. These genes are in consistence with the assembly of the recently published genome [28]. The two sequences, as well as MyoG that has also been derived from genomic data [38], are therefore predicted sequences that have not been verified by complete cDNAs. The Japanese cDNA project $[21,23]$ includes only small parts of these new myosins, which are, however, consistent with the predicted sequences. The Japanese cDNA project also includes at least fragments of all other myosins. No additional myosin genes have been found in the genome of Dictyostelium, and thus the reported " $m y L^{\prime}$ gene locus [27] might have originated from experimental artefacts.

The Dictyostelium calmodulin-related genes have been identified in an iterated TBLASTN search of the completed Dictyostelium genome starting with the protein sequence of CalA. Thus, all solely EF-hand motif-containing proteins have been collected (Table 3). The predicted sequences have been verified by searches against the Japanese cDNA database [23]. The EF-hand containing proteins from Saccharomyces cerevisiae, Schizosaccharomyces pombe, Caenorhabditis elegans, Drosophila melanogaster, and Homo sapiens have been obtained in iterative TBLASTN searches of the corresponding genomes. Specific myosin light chains from other organisms have been obtained from the protein database at NCBI.

\section{Building trees}

The complete analysis of the myosin motor domains derived from the NCBI non-redundant database and the EST and genomic sequences of more than 270 eukaryotes will be published elsewhere (Kollmar, unpublished data). All these myosin sequences, including the Dictyostelium myosins, together with their accession numbers and additional references will be accessible through the newly designed CyMoBase [[39], F. Odronitz and M. Kollmar, submitted]. The database comprises over 1700 myosin sequences (Feb. 2006) that have been used for the phylogenetic classification of the Dictyostelium myosins. The underlying phylogenetic tree has been built of a structureguided multiple sequence alignment. The phylogenetic trees of the class-V/-VIII/-XI and the class-VII/-X/-XV/-XXII myosins have been constructed from corresponding sequences of this alignment. All phylogenetic trees are unrooted and were generated using neighbour joining and the Bootstrap (1,000 replicates) method as implemented in ClustalW [standard settings, [40]] and drawn by using TreeView [41].

The phylogenetic tree of the calmodulin-related proteins has been calculated based on a manual sequence alignment. The manual sequence alignment has been improved by iteratively creating phylogenetic trees and adjusting the alignment. The resulting phylogenetic tree is unrooted and was generated using neighbour joining and 
the Bootstrap (1,000 replicates) method as implemented in ClustalW and drawn by using TreeView.

\section{Domain and motif prediction}

Protein domains were predicted using the SMART $[42,43]$ and Pfam $[44,45]$ web server. The prediction of protein motifs (coiled coils, leucine zipper, prenyl-group binding motifs) is mainly based on the results of the predict-protein server [46,47]. The IQ-motifs and N-terminal domains were predicted manually based on the homology to similar domains of other myosins included in the multiple sequence alignment of the myosins. The recognition motifs included in the SMART and Pfam databases are too restrictive, as the motifs have been created based on the small datasets available some years ago.

\section{Abbreviations}

SH3, src homology 3; $\mathrm{PH}$, pleckstrin homology; DIL, dilute; FERM, band 4.1, ezrin, radixin, and moesin; MyTH4, myosin tail homology 4; RhoGEF, Rho GDP/GTP exchange factor; CBP, calcium-binding protein; MLC, myosin light chain; ELC, essential light chain; RLC, regulatory light chain; $\mathrm{Chr}$, chromosome.

\section{Authors' contributions}

M.K. performed all analyses and wrote the manuscript.

\section{Additional material}

\section{Additional File 1}

Complete phylogenetic tree of the class-V, -VIII, and -XI myosins. Click here for file

[http://www.biomedcentral.com/content/supplementary/14712164-7-183-S1.pdf]

\section{Additional File 2}

Complete phylogenetic tree of the class-VII, $-X,-X V$ and $-X X I I$ myosins. Click here for file

[http://www.biomedcentral.com/content/supplementary/14712164-7-183-S2.pdf]

\section{Additional File 3}

Complete phylogenetic tree of the calmodulin related proteins. Click here for file

[http://www.biomedcentral.com/content/supplementary/14712164-7-183-S3.pdf]

\section{Acknowledgements}

M.K. is supported by a Liebig Stipendium of the Fonds der Chemischen Industrie, which is in part financed by the BMBF.

\section{References}

I. Schliwa M, Woehlke G: Molecular motors. Nature 2003, 422(6933):759-765.

2. Vale RD: The molecular motor toolbox for intracellular transport. Cell 2003, I I 2(4):467-480.
3. Bement WM, Mooseker MS: TEDS rule: a molecular rationale for differential regulation of myosins by phosphorylation of the heavy chain head. Cell Motil Cytoskeleton 1995, 3 I (2):87-92.

4. Williams SA, Gavin RH: Myosin genes in Tetrahymena. Cell Motil Cytoskeleton 2005, 6 I (4):237-243.

5. Berg JS, Powell BC, Cheney RE: A millennial myosin census. Mol Biol Cell 200I, I 2(4):780-794.

6. Foth $B J$, Goedecke MC, Soldati $D$ : New insights into myosin evolution and classification. Proc Natl Acad Sci U S A 2006, I03(10):368I-3686.

7. Richards TA, Cavalier-Smith T: Myosin domain evolution and the primary divergence of eukaryotes. Nature 2005, 436(7054): III3-III8.

8. Loftus B, Anderson I, Davies R, Alsmark UC, Samuelson J, Amedeo P, Roncaglia P, Berriman M, Hirt RP, Mann B], Nozaki T, Suh B, Pop M, Duchene M, Ackers J, Tannich E, Leippe M, Hofer M, Bruchhaus I, Willhoeft U, Bhattacharya A, Chillingworth T, Churcher C, Hance Z, Harris B, Harris D, Jagels K, Moule S, Mungall K, Ormond D, Squares R, Whitehead S, Quail MA, Rabbinowitsch E, Norbertczak H, Price C, Wang Z, Guillen N, Gilchrist C, Stroup SE, Bhattacharya S, Lohia A, Foster PG, Sicheritz-Ponten T, Weber C, Singh U, Mukherjee C, ElSayed NM, Petri WAJ, Clark CG, Embley TM, Barrell B, Fraser CM, Hall N: The genome of the protist parasite Entamoeba histolytica. Nature 2005, 433(7028):865-868.

9. Goffeau A, Barrell BG, Bussey H, Davis RW, Dujon B, Feldmann $H$, Galibert F, Hoheisel JD, Jacq C, Johnston M, Louis EJ, Mewes HW, Murakami Y, Philippsen P, Tettelin H, Oliver SG: Life with $\mathbf{6 0 0 0}$ genes. Science 1996, 274(5287):546, 563-7.

10. Soldati T, Geissler H, Schwarz EC: How many is enough? Exploring the myosin repertoire in the model eukaryote Dictyostelium discoideum. Cell Biochem Biophys 1999, 30(3):389-4II.

II. Titus MA: A class VII unconventional myosin is required for phagocytosis. Curr Biol 1999, 9(22):1297-1303.

12. Peterson MD, Urioste AS, Titus MA: Dictyostelium discoideum myoJ: a member of a broadly defined myosin $\mathbf{V}$ class or a class XI unconventional myosin? J Muscle Res Cell Motil 1996, I 7(4):4I I-424.

13. Hammer JA, Jung G: The sequence of the dictyostelium myo J heavy chain gene predicts a novel, dimeric, unconventional myosin with a heavy chain molecular mass of $258 \mathbf{~ k D a}$. J Biol Chem 1996, 27I(I2):7120-7I27.

14. Holmes KC: The swinging lever-arm hypothesis of muscle contraction. Curr Biol I997, 7(2):R I I2-8.

15. Trybus KM: Role of myosin light chains. J Muscle Res Cell Motil 1994, I 5(6):587-594.

16. Herm-Gotz A, Weiss S, Stratmann R, Fujita-Becker S, Ruff C, Meyhofer E, Soldati T, Manstein DJ, Geeves MA, Soldati D: Toxoplasma gondii myosin $A$ and its light chain: a fast, single-headed, plus-end-directed motor. Embo J 2002, 2 I(9):2। 49-2। 58.

17. Wang ZY, Sakai J, Matsudaira PT, Baines IC, Sellers JR, Hammer JA, Korn ED: The amino acid sequence of the light chain of Acanthamoeba myosin IC. J Muscle Res Cell Motil 1997, I 8(3):395-398.

18. De La Roche MA, Lee SF, Cote GP: The Dictyostelium class I myosin, MyoD, contains a novel light chain that lacks highaffinity calcium-binding sites. Biochem J 2003, 374(Pt 3):697-705.

19. Crawley SW, de la Roche MA, Lee SF, Li Z, Chityat S, Smith SP, Cote GP: Identification and characterization of an $8 \mathrm{kDa}$ light chain associated with dictyostelium discoideum MyoB, a class I myosin. J Biol Chem 2006.

20. Titus MA, Kuspa A, Loomis WF: Discovery of myosin genes by physical mapping in Dictyostelium. Proc Natl Acad Sci U S A 1994, 9I(20):9446-9450.

21. Urushihara H, Morio T, Saito T, Kohara Y, Koriki E, Ochiai H, Maeda M, Williams JG, Takeuchi I, Tanaka Y: Analyses of cDNAs from growth and slug stages of Dictyostelium discoideum. Nucleic Acids Res 2004, 32(5): 1647-1653.

22. DictyBase [http://dictybase.org/strain history.htm]

23. Dictyostelium discoideum cDNA Project [http://dicty cdb.biol.tsukuba.ac.jp/]

24. Tuxworth RI, Weber I, Wessels D, Addicks GC, Soll DR, Gerisch G, Titus MA: A role for myosin VII in dynamic cell adhesion. Curr Biol 200I, I I (5):3 I 8-329.

25. de la Roche MA, Cote GP: Regulation of Dictyostelium myosin I and II. Biochim Biophys Acta 200 I, I 525(3):245-26I. 
26. Geissler $\mathrm{H}$, Ullmann R, Soldati $\mathrm{T}$ : The tail domain of myosin $\mathbf{M}$ catalyses nucleotide exchange on Racl GTPases and can induce actin-driven surface protrusions. Traffic 2000, I(5):399-4I0

27. Titus MA, Warrick HM, Spudich JA: Multiple actin-based motor genes in Dictyostelium. Cell Regul 1989, I(I):55-63.

28. Eichinger L, Pachebat JA, Glockner G, Rajandream MA, Sucgang $R$ Berriman M, Song J, Olsen R, Szafranski K, Xu Q, Tunggal B, Kummerfeld S, Madera M, Konfortov BA, Rivero F, Bankier AT, Lehmann R, Hamlin N, Davies R, Gaudet P, Fey P, Pilcher K, Chen G, Saunders D, Sodergren E, Davis P, Kerhornou A, Nie X, Hall N, Anjard C, Hemphill L, Bason N, Farbrother P, Desany B, Just E, Morio T, Rost R, Churcher C, Cooper J, Haydock S, van Driessche N, Cronin A, Goodhead I, Muzny D, Mourier T, Pain A, Lu M, Harper D, Lindsay R, Hauser H, James K, Quiles M, Madan Babu M, Saito T, Buchrieser C, Wardroper A, Felder M, Thangavelu M, Johnson D, Knights A, Loulseged H, Mungall K, Oliver K, Price C, Quail MA, Urushihara H, Hernandez J, Rabbinowitsch E, Steffen D, Sanders M, Ma J, Kohara Y, Sharp S, Simmonds M, Spiegler S, Tivey A, Sugano S, White B, Walker D, Woodward J, Winckler T, Tanaka Y, Shaulsky G, Schleicher M, Weinstock G, Rosenthal A, Cox EC, Chisholm RL, Gibbs R, Loomis WF, Platzer M, Kay RR, Williams J, Dear PH, Noegel AA, Barrell B, Kuspa A: The genome of the social amoeba Dictyostelium discoideum. Nature 2005, 435(7038):43-57.

29. Xie P, Dou SX, Wang PY: Model for kinetics of myosin-V molecular motors. Biophys Chem 2005.

30. Yamashita RA, Sellers JR, Anderson JB: Identification and analysis of the myosin superfamily in Drosophila: a database approach. J Muscle Res Cell Motil 2000, 2 I (6):49I-505.

31. Sweeney HL, Rosenfeld SS, Brown F, Faust L, Smith J, Xing J, Stein LA, Sellers JR: Kinetic tuning of myosin via a flexible loop adjacent to the nucleotide binding pocket. J Biol Chem 1998, 273(I I):6262-6270.

32. De La Cruz EM, Wells AL, Rosenfeld SS, Ostap EM, Sweeney HL: The kinetic mechanism of myosin V. Proc Natl Acad Sci U S A 1999, 96(24): |3726-|373|.

33. Furch M, Geeves MA, Manstein DJ: Modulation of actin affinity and actomyosin adenosine triphosphatase by charge changes in the myosin motor domain. Biochemistry 1998, 37(18):6317-6326.

34. Kollmar M, Durrwang U, Kliche W, Manstein DJ, Kull FJ: Crystal structure of the motor domain of a class-I myosin. Embo 2002, 2 I (I I ):25I7-2525

35. Tang N, Ostap EM: Motor domain-dependent localization of myol b (myr-I). Curr Biol 200I, I I ( 14): I I3 I-I I35.

36. Menetrey J, Bahloul A, Wells AL, Yengo CM, Morris CA, Sweeney HL, Houdusse A: The structure of the myosin VI motor reveals the mechanism of directionality reversal. Nature 2005 435(7043): 779-785

37. Sakamoto $H$, Nishio $K$, Tomisako $M$, Kuwayama $H$, Tanaka $Y$, Suetake I, Tajima S, Ogihara S, Coukell B, Maeda M: Identification and characterization of novel calcium-binding proteins of Dictyostelium and their spatial expression patterns during development. Dev Growth Differ 2003, 45(5-6):507-5I4.

38. Glockner G, Eichinger L, Szafranski K, Pachebat JA, Bankier AT, Dear $\mathrm{PH}$, Lehmann R, Baumgart C, Parra G, Abril JF, Guigo R, Kumpf K, Tunggal B, Cox E, Quail MA, Platzer M, Rosenthal A, Noegel AA Sequence and analysis of chromosome 2 of Dictyostelium discoideum. Nature 2002, 4I 8(6893):79-85.

39. CyMoBase [http://www.motorprotein.de/CyMoBase/]

40. Chenna R, Sugawara H, Koike T, Lopez R, Gibson TJ, Higgins DG Thompson JD: Multiple sequence alignment with the Clusta series of programs. Nucleic Acids Res 2003, 3 I (13):3497-3500.

4I. Page RD: TreeView: an application to display phylogenetic trees on personal computers. Comput Appl Biosci 1996, I 2(4):357-358.

42. Letunic I, Copley RR, Schmidt S, Ciccarelli FD, Doerks T, Schultz J, Ponting CP, Bork P: SMART 4.0: towards genomic data integration. Nucleic Acids Res 2004, 32(Database issue):D I 42-4.

43. SMART [http://smart.embl-heidelberg.de/]

44. Bateman A, Coin L, Durbin R, Finn RD, Hollich V, Griffiths-Jones S, Khanna A, Marshall M, Moxon S, Sonnhammer EL, Studholme D, Yeats C, Eddy SR: The Pfam protein families database. Nucleic Acids Res 2004, 32(Database issue):D I38-4I.

45. Pfam [http://www.sanger.ac.uk/Software/Pfam/]
46. Rost B, Liu J: The PredictProtein server. Nucleic Acids Res 2003 , 3I(13):3300-3304

47. PredictProtein [http://www.predictprotein.org/]

48. Jung G, Saxe CL, Kimmel AR, Hammer JA: Dictyostelium discoideum contains a gene encoding a myosin I heavy chain. Proc Natl Acad Sci U S A 1989, 86( I6):6।86-6190.

49. Peterson MD, Novak KD, Reedy MC, Ruman JI, Titus MA: Molecular genetic analysis of myoC, a Dictyostelium myosin I. J Cell Sci 1995, 108 ( Pt 3): 1093-II03.

50. Jung G, Fukui Y, Martin B, Hammer JA: Sequence, expression pattern, intracellular localization, and targeted disruption of the Dictyostelium myosin ID heavy chain isoform. J Biol Chem 1993, 268(20): |498|-|4990.

51. Urrutia RA, Jung G, Hammer JA: The Dictyostelium myosin IE heavy chain gene encodes a truncated isoform that lacks sequences corresponding to the actin binding site in the tail. Biochim Biophys Acta 1993, I I 73(2):225-229.

52. Yazu M, Adachi H, Sutoh K: Novel Dictyostelium unconventional myosin MyoK is a class I myosin with the longest loopI insert and the shortest tail. Biochem Biophys Res Commun 1999, 255(3):7|I-7|6.

53. Schwarz EC, Geissler H, Soldati T: A potentially exhaustive screening strategy reveals two novel divergent myosins in Dictyostelium. Cell Biochem Biophys 1999, 30(3):4I 3-435.

54. Warrick HM, De Lozanne A, Leinwand LA, Spudich JA: Conserved protein domains in a myosin heavy chain gene from Dictyostelium discoideum. Proc Natl Acad Sci U S A 1986, 83(24):9433-9437.

55. Oishi N, Adachi H, Sutoh K: Novel Dictyostelium unconventional myosin, MyoM, has a putative RhoGEF domain. FEBS Lett 2000, 474(I): 16-22.

56. Pollenz RS, Chisholm RL: Dictyostelium discoideum essential myosin light chain: gene structure and characterization. Cell Motil Cytoskeleton I991, 20(2):83-94.

57. Chisholm RL, Rushforth AM, Pollenz RS, Kuczmarski ER, Tafuri SR Dictyostelium discoideum myosin: isolation and characterization of cDNAs encoding the essential light chain. Mol Cell Biol I988, 8(2):794-80I

58. Tafuri SR, Rushforth AM, Kuczmarski ER, Chisholm RL: Dictyostelium discoideum myosin: isolation and characterization of cDNAs encoding the regulatory light chain. Mol Cell Biol I989, 9(7):3073-3080.

59. Goldhagen $\mathrm{H}$, Clarke M: Identification of the single gene for calmodulin in Dictyostelium discoideum. Mol Cell Biol 1986, 6(5): $185|-| 854$

60. Rosel D, Puta F, Blahuskova A, Smykal P, Folk P: Molecular characterization of a calmodulin-like dictyostelium protein CalB. FEBS Lett 2000, 473(3):323-327.

6I. Coukell B, Moniakis J, Grinberg A: Cloning and expression in Escherichia coli of a cDNA encoding a developmentally reg. ulated $\mathrm{Ca}(2+)$-binding protein from Dictyostelium discoideum. FEBS Lett 1995, 362(3):342-346

62. Andre B, Noegel AA, Schleicher M: Dictyostelium discoideum contains a family of calmodulin-related EF-hand proteins that are developmentally regulated. FEBS Lett 1996, 382(I2): $198-202$.

63. Han YH, Kang SO: Cloning of a cDNA encoding a new calciumbinding protein from Dictyostelium discoideum and its developmental regulation. FEBS Lett 1998, 44 I(2):302-306.

64. Dorywalska M, Coukell B, Dharamsi A: Characterization and hetereologous expression of cDNAs encoding two novel closely related $\mathrm{Ca}(2+)$-binding proteins in Dictyostelium discoideum. Biochim Biophys Acta 2000, I 496(2-3):356-36I.

65. Coukell B, Cameron A, Perusini S, Shim K: Disruption of the NCSI/frequenin-related ncsA gene in Dictyostelium discoideum accelerates development. Dev Growth Differ 2004, 46(5):449-458.

66. Abe F, Maeda Y: Specific expression of a gene encoding a novel calcium-binding protein, CAF-I, during transition of Dictyostelium cells from growth to differentiation. Dev Growth Differ 1995, 37:39-48. 